\title{
Choledochal cysts: lessons from a 20 year experience
}

\author{
M D Stringer, A Dhawan, M Davenport, G Mieli-Vergani, A P Mowat, E R Howard
}

\begin{abstract}
Cystic dilatation of the biliary tree is a rare congenital anomaly. To determine mode of presentation, diagnostic pitfalls, and long term outcome after surgery, 78 children ( 57 girls, 21 boys) with choledochal cyst treated between 1974 and 1994 were reviewed. Anatomical types were: Ic $(n=44)$, If $(n=28)$, IVa $(n=4)$, and V $(n=2)$; a common pancreaticobiliary channel was identified in $76 \%$ patients. Age at presentation ranged from 0-16 (median 2.2) years, six patients being diagnosed by prenatal ultrasonography. Of the 72 patients diagnosed postnatally, $50(69 \%)$ presented with jaundice, associated with abdominal pain in 25 or a palpable mass in three, 13 $(18 \%)$ presented with pain alone, and two (3\%) with a palpable mass. The classic triad of jaundice, pain, and a right hypochondrial mass was present in only four $(6 \%)$. Four children presented acutely after spontaneous perforation of a choledochal cyst, two presented with ascites and one cyst was discovered incidentally. Plasma and/or biliary amylase values were raised in 30 of 31 patients investigated for abdominal pain; seven had evidence of pancreatitis at

pathological features of the condition frequently include an anomalous junction of the pancreatic and common bile ducts, distal common bile duct stenosis, intrahepatic duct dilatation, and abnormal hepatic histology. Most cases present in childhood, classically with jaundice, pain, and an abdominal mass. The infrequency of this triad, the presence of serious delays in diagnosis, and the impact of prenatal diagnosis prompted us to review our experience.

Patients and methods

Between 1974 and 1994, 78 children (57 girls, 21 boys) with choledochal cysts were referred to King's College Hospital, London, for treatment. Medical records, imaging studies, and biochemical data were retrospectively analysed and supplemented in some cases by information from general practitioners. Liver function tests, plasma amylase measurements, and abdominal ultrasonography were routinely performed. Biliary anatomy was defined further by percutaneous transhepatic cholangiography, endoscopic retrograde cholangiopancreatography (ERCP), or operative cholangiography. Computed tomography and radionucleide excretion scans were used in selected cases.
\end{abstract} operation. In 35 of $67(52 \%)$ patients referred without previous surgery, symptoms had been present for more than one month, and in 14 of them for more than one year, before diagnosis. Delayed referral was due to misdiagnosis as hepatitis $(n=12)$, incomplete investigation of abdominal pain $(n=6)$, and failure to note the significance of ultrasonographic findings $(n=10)$. Two patients referred late died from liver failure. Of the 76 patients with type I or IV cysts, 59 underwent radical cyst excision and hepaticojejunostomy as a primary procedure and $\mathbf{1 0}$ as a secondary operation after previously unsuccessful surgery. Sixteen patients have been lost to follow up but most of the remainder are well after a mean period of 4.1 (0.1-13) years. Choledochal cysts are often misdiagnosed, but prognosis is excellent if radical excision is performed. (Arch Dis Child 1995; 73: 528-531)

Keywords: choledochal cyst, jaundice, pancreatitis.

Choledochal cyst, a cystic dilatation of the biliary tree, is a rare congenital abnormality of unknown aetiology, more common in females, with an estimated incidence in Western populations of one in 100-150 000 live births. ${ }^{1}$ The

\section{Results}

ANATOMICAL CLASSIFICATION

The anatomical distribution of bile duct cysts based on Todani's classification ${ }^{2}$ is shown in fig 1. Included in the type If group is one child with dilatation of the pancreatic and common bile ducts caused by a stone impacted in a common pancreaticobiliary channel (sometimes referred to as a 'forme fruste' choledochal cyst) and another with a choledochal diverticulum contiguous with a fusiform dilatation.

The presence of a common pancreaticobiliary channel identified by cholangiography was specifically recorded in $\mathbf{5 5}$ patients and was found in $42(76 \%)$. Other biliary abnormalities were documented in two patients, one previously reported child with a non-communicating multiseptate gall bladder ${ }^{3}$ and another with multiple accessory bile ducts.

\section{PRESENTING CLINICAL FEATURES}

Age at presentation ranged from 0-16 (median $2 \cdot 2$ ) years; more than two thirds of patients presented by 5 years of age (fig 2). In six patients, the choledochal cyst was discovered by antenatal ultrasonography as early as 16 weeks' gestation (table 1). Four of these patients developed jaundice with abnormal 


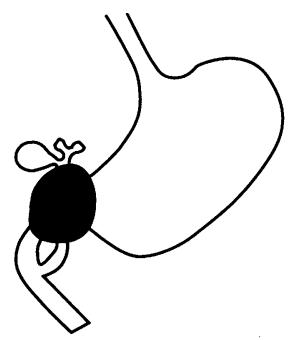

Type Ic, cystic dilatation of the common bile duct $(n=44)$

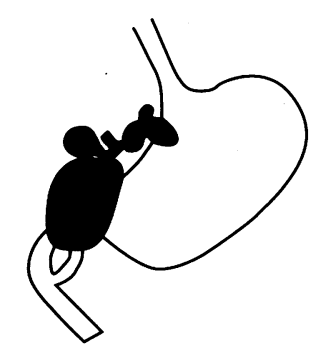

Type IVa, intrahepatic and extrahepatic cysts $(n=4)$

Figure 1 Anatomical classification of bile duct cysts $(n=78)$.

biochemical liver function tests. Of the 72 patients presenting postnatally, 50 (69\%) presented with jaundice, associated with abdominal pain in 25 or a palpable mass in three; in small infants, jaundice was usually persistent but in older children, in all except one, the jaundice was intermittent. Thirteen $(18 \%)$ patients presented only with abdominal pain, which was frequently recurrent, and two (3\%) only with a mass. The classic triad of jaundice, pain, and a right hypochondrial mass was present in only four (6\%) patients (fig 3).

Plasma and/or biliary amylase values were recorded in 31 of the 38 patients with pain: 23 had raised plasma and biliary levels and seven of the remainder had markedly raised biliary amylase levels. Seven of these patients had evidence of pancreatitis at operation.

Four children presented acutely after spontaneous perforation of a choledochal cyst: three developed biliary peritonitis and the other had an acute onset of abdominal pain and fever due to a retroperitoneal perforation. Two children presented with abdominal distension due to ascites: one was in liver failure and the other also had melaena from variceal haemorrhage. In one infant, a choledochal cyst was detected by abdominal ultrasonography after an unexplained neonatal intraperitoneal haemorrhage.

Table 1 Clinical features of antenatally diagnosed choledochal cysts $(n=6)$

\begin{tabular}{llllcc}
\hline $\begin{array}{l}\text { Patient } \\
\text { No }\end{array}$ & $\begin{array}{l}\text { Gestational age } \\
\text { at detection (weeks) }\end{array}$ & $\begin{array}{l}\text { Cyst } \\
\text { type }\end{array}$ & Postnatal symptoms & $\begin{array}{l}\text { Biliary } \\
\text { amylase (IU/) }\end{array}$ & $\begin{array}{l}\text { Age at } \\
\text { operation }\end{array}$ \\
\hline 1 & 28 & V & Asymptomatic & & - \\
2 & $16^{\star}$ & Ic & Persistent jaundice & 6 & 3 Weeks \\
3 & 20 & Ic & Persistent jaundice & $<10$ & 17 Days \\
4 & 18 & Ic & Recurrent jaundice & 7 & 3 Weeks \\
5 & $17^{\star}$ & Ic & Jaundice & 50 & 7 Days \\
6 & 16 & Ic & Asymptomatic & 7000 & Months \\
\hline
\end{tabular}

^Initially considered to have a 'double-bubble' on ultrasound.

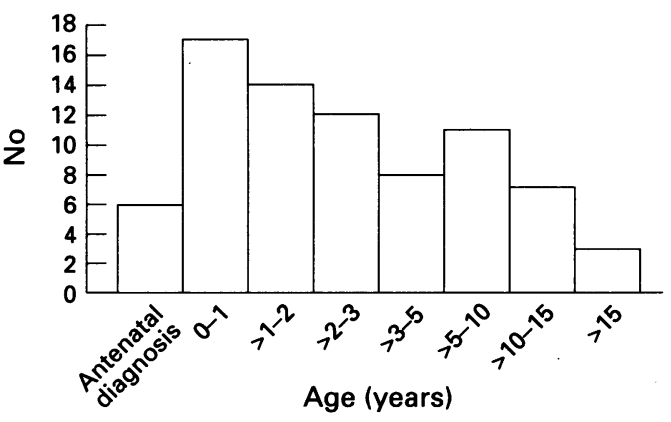

Figure 2 Choledochal cysts: age at presentation $(n=78)$.

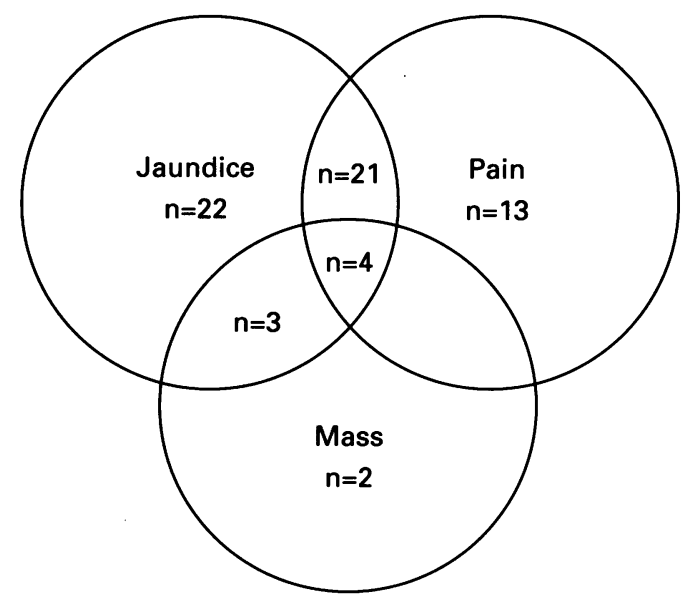

\section{- Antenatal diagnosis 6 \\ - Acute abdomen 4 \\ - Others 3}

Figure 3 Presenting symptoms in 78 children with choledochal cysts.

Additional presenting symptoms included vomiting in seven patients, fever in another seven, two of whom had cholangitis, and failure to thrive in four.

\section{ASSOCIATED CONDITIONS}

In 67 patients who had not previously undergone surgery, there were five with gall stones, two with pancreatic duct stones, four with evidence of portal hypertension, and two with biliary cirrhosis. In contrast, of 11 children referred or representing after previously inadequate surgery, five had gall stones, four had portal hypertension, and two had biliary cirrhosis.

Additional congenital anomalies were identified in nine patients: renal/urinary tract malformations in five, cardiac anomalies in two, and one child each with intestinal malrotation and vertebral anomalies.

\section{DELAYED REFERRAL AND DIAGNOSIS}

In $35(52 \%)$ of the 67 patients who had not previously undergone surgery, symptoms had been present for more than one month, and in 14 of them for more than one year, before diagnosis. Reasons for delayed diagnosis and 
Table 2 Causes of delayed diagnosis/referral of children with choledochal cyst

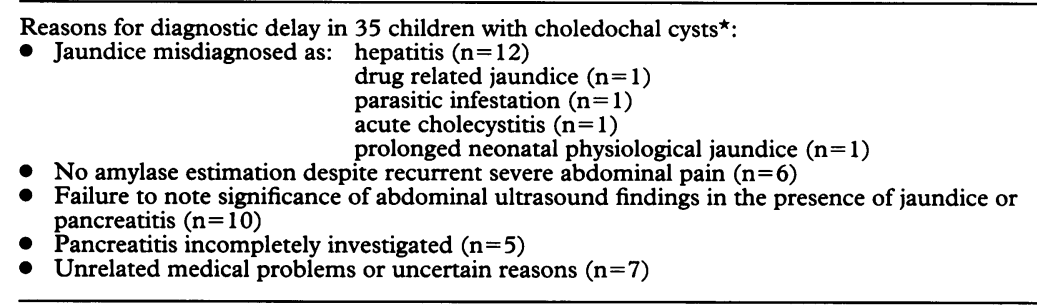

^More than one reason present in some patients.

referral are shown in table 2. Twelve patients with jaundice with or without pain were initially diagnosed as having hepatitis yet none had serological confirmation. A 10 year old boy with progressive jaundice was treated with steroids after a liver biopsy had suggested chronic active hepatitis. Despite sonographic evidence of extrahepatic bile duct dilatation, he was not referred until two months later by which time he had developed uncontrolled biliary sepsis and terminal liver failure. In four other children, jaundice was wrongly attributed to other causes. For example, a 2 year old Taiwanese girl was treated for presumed Clonorchis sinensis biliary infestation before her abdominal ultrasound findings were reinterpreted. In six children with repeated attacks of abdominal pain, all of whom had a common pancreaticobiliary channel, there were delays of up to three years before a plasma amylase level was recorded. Five patients with acute or recurrent pancreatitis were only referred for detailed investigation several months later and in 10 patients with jaundice and/or pancreatitis the finding of a dilated common bile duct at abdominal ultrasonography failed to prompt early referral for further investigation.

\section{MANAGEMENT AND OUTCOME}

Of 76 patients with type I or IV cysts, 59 underwent radical cyst excision with Rouxen-Y hepaticojejunostomy as a primary procedure. ${ }^{1}$ In a further 10 patients this was performed as a secondary procedure either after previously inadequate surgery $(n=8)$ or after preliminary $\mathrm{T}$ tube drainage of a complicated choledochal cyst $(n=2)$. Five patients underwent biliary bypass procedures, principally because cyst excision was technically too hazardous, and one girl was treated by liver transplantation after failed surgery elsewhere. Two patients died from liver failure and portal hypertension, one before definitive surgery was possible (see above) and the other after a biliary bypass procedure.

Of the two children with type $\mathrm{V}$ cysts, one remains under review and is asymptomatic three years after antenatal diagnosis and the other, with portal hypertension, has been lost to follow up.

Surgical complications occurred in seven of $59(12 \%)$ patients after primary cyst excision: haemorrhage requiring reoperation in two, adhesive bowel obstruction in two, biliary leak, pancreatitis, and intra-abdominal sepsis. A total of 16 patients, mostly from abroad, have been lost to follow up. The remaining children are well after a mean period of $4 \cdot 1$ years (0.1-13 years) after definitive surgery; biochemical liver function tests are normal in $\mathbf{4 2}$ of 43 with recent results (including those undergoing surgery after prenatal diagnosis). One child with a type IVa cyst has had cholangitis and persistently abnormal liver function related to intrahepatic cholestasis. Five children have experienced intermittent episodes of abdominal pain: one has an ectatic pancreatic duct, one intrahepatic bile duct ectasia, and detailed investigations in the others are normal.

\section{Discussion}

A choledochal cyst is a rare but important cause of jaundice and abdominal pain. Older children are more likely to present with pancreatitis and infants with jaundice. ${ }^{45}$ In contrast to adults, the classical presentation of a choledochal cyst with jaundice, abdominal pain, and a right hypochondrial mass is rare in children, and was documented in only four $(6 \%)$ of our patients. This compares with four of $52(8 \%)$ children reported by Joseph from Singapore. ${ }^{6}$ Diagnostic delay appears to be common and may have fatal consequences but is potentially avoidable. Complications of undiagnosed cysts include pancreatitis, spontaneous perforation, cholelithiasis, cholangitis, secondary biliary cirrhosis, portal hypertension, and malignancy.

Choledochal cyst should always be considered in the differential diagnosis of jaundice and pancreatitis. Both conditions require careful detailed anatomical investigation of the patient with high resolution fasting abdominal ultrasonography which, in the case of a choledochal cyst, is frequently diagnostic. ${ }^{7}$ The common bile duct diameter measures less than $3.5 \mathrm{~mm}$ in healthy children and less than $2 \mathrm{~mm}$ in infants. ${ }^{8} \mathrm{~A}$ clinical diagnosis of hepatitis without serological confirmation demands further investigation and, in the presence of sonographically dilated bile ducts, is an indication for cholangiography. Although recurrent abdominal pain and pancreatitis has long been recognised as a complication of choledochal cyst, ${ }^{910}$ this mode of presentation deserves wider recognition. Children with severe or recurrent abdominal pain should have a plasma amylase level measured, even though the yield from this investigation in unselected children with recurrent abdominal pain is extremely low. ${ }^{11}$ The hyperamylasaemia associated with choledochal cysts is due at least in part to. diffusion of amylase through the denuded epithelium of the cyst wall in those with a common channel and high bilary amylase level ${ }^{12}$ ('biochemical' pancreatitis) but clinically severe pancreatitis may occur. With the availability of modern paediatric duodenoscopes, ERCP should be more widely employed in the investigation of unexplained pancreatitis searching for anatomical abnormalities such as a common pancreaticobiliary channel. ${ }^{10}$

Advances in antenatal diagnosis have led to several reports describing the management of infants with a prenatally diagnosed 
choledochal cyst. ${ }^{413}$ We believe that such patients should be treated by early surgery to avoid the risk of complications. Secondary biliary cirrhosis may develop in early childhood and liver failure has been reported in a 5 month old infant with an untreated choledochal cyst. ${ }^{14}$ All four cyst perforations in this series occurred in children of 6 months to 3 years and malignant change has also been recorded in childhood. ${ }^{15}$ Furthermore, a neonate with conjugated hyperbilirubinaemia and cystic dilatation of the biliary tree may have a variant of extrahepatic biliary atresia which must be treated by early surgery. ${ }^{416}$

Radical cyst excision and reconstruction with a Roux-en-Y hepaticojejunostomy is now established as the treatment of choice for the common types of choledochal cyst. ${ }^{167}$ Cyst excision eliminates almost all the potential complications of choledochal cysts and can be performed safely with no mortality and minimal morbidity even in small infants. There is some evidence that even in patients with biliary cirrhosis and portal hypertension, disease regression is possible after surgical treatment. $^{17}$

1 Howard ER. Choledochal cysts. In: Howard ER, ed. Surgery of liver disease in children. Oxford: ButterworthHeinemann, 1991: 78-90.

2 Todani $T$, Watanabe $Y$, Narusue $M$, Tabuchi $K$, Okajima $K$. Classification, operative procedures and review of thirty seven cases including cancer arising from

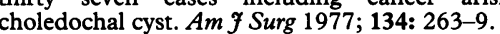

3 Tan CEL, Howard ER, Driver M, Murray-Lyon IM. Noncommunicating multiseptate gall bladder and choledochal cyst: a case report and review of publications. Gut 1993; 34: 853-6.

4 Bancroft JD, Bucuvalas JC, Ryckman FC, Dudgeon DL, Saunders RC, Schwarz KB. Antenatal diagnosis of choledochal cyst. $\mathcal{f}$ Pediatr Gastroenterol Nutr 1994; 18: 142-5.

5 Davenport $M$, Stringer MD, Howard ER. Biliary amylase and congenital choledochal dilatation. $\mathcal{F}$ Pediatr Surg 1995; 30: 474-7.

6 Joseph VT. Surgical techniques and long-term results in the treatment of choledochal cyst. $\mathcal{F}$ Pediatr Surg 1990; 25: treatm

7 Tan KC, Howard ER. Choledochal cyst: a 14-year surgical experience with 36 patients. Br $\mathcal{F}$ Surg 1988; 75: 892-5.

8 Hernanz-Schulman M, Ambrosino MM, Freeman PC, Quinn CB. Common bile duct in children: sonographic
Qunand dimensions. Radiology 1995; 195: 193-5.

9 Raffensperger JG, Given GZ, Warrner RA. Fusiform dilatation of the common bile duct with pancreatitis. $\mathcal{F}$ Pediatr Surg 1973; 8: 907-10.

10 Okada A, Oguchi Y, Kamata S, Ikeda Y, Kawashima Y, Saito R. Common channel syndrome - diagnosis with endoscopic retrograde cholangiopancreatography and surgical management. Surgery 1983; 93: 634-42.

11 Wheeler RA, Colquhoun-Flannery WA, Johnson CD. Plasma amylase estimation in recurrent abdominal pain in children. Ann R Coll Surg Engl 1992; 74: 335-6.

12 Stringel G, Filler RM. Fictitious pancreatitis in choledochal cyst. $\mathcal{F}$ Pediatr Surg 1982; 17: 359-61.

13 Schroeder D, Smith L, Prain HC. Antenatal diagnosis of choledochal cyst at 15 weeks' gestation: etiologic implications and management. f Pediatr Surg 1989; 24: cations

14 Harris VJ, Kahler J. Choledochal cyst. Delayed diagnosis in a jaundiced infant. Pediatrics 1978; 62: 235-7.

15 Iwai N, Deguchi E, Yanagihara J, et al. Cancer arising in a choledochal cyst in a 12-year-old girl. $\mathcal{F}$ Pediatr Surg 1990; 25: 1261-3.

16 Greenholz SK, Lilly JR, Shikes RH, Hall RJ. Biliary atresia in the newborn. $\mathcal{F}$ Pediatr Surg 1986; 21 : 11 147-8.

17 Yeong ML, Nicholson GI, Lee SP. Regression of biliary cirrhosis following choledochal cyst drainage. Gastroenterology 1982; 82: 332-5. 